\title{
La coherència iconogràfica de la segona visió mitològica de Curial
}

\author{
Matilde Cortés Cañagueral
}

\section{LA PRESÈNCIA DE BACUS}

Com ja és ben sabut, Francisco Rico $(1982,89-90)$ creié detectar en el pròleg al llibre primer del Curial e Güelfa $(1930-33)^{1}$ una eventual lectura del Petrarca llatí, que posteriorment ha anat confirmant-se en altres episodis de la novel-la (Turró 1991).

Confesse que no podia estar-me de creure que l'anònim no se n'hagués aprofitat, encara que fos en el seu rerefons mental, d'algun element formal o de contingut del Secretum, així que, rellegint-lo, vaig decidir de confrontar-lo amb el Curial, més amb l'ànim de trobar concomitàncies aclaridores que donaren llum a alguns dels passatges més desconcertants que de cercar-hi veritables manlleus.

Una simple recerca de paral-lelismes formals ens pot dur a acceptar que ambdós autors s'aproximaren — per bé que no volgueren adscriure's obertament-a l'oraculum - tipus de somni en què, segons Macrobi, una figura venerable dóna un consell (Lewis 1985, 66)-, trobant-hi el marc literari idoni que els serví d'excusa per a reflexionar sobre els comportaments humans i proposarhi alternatives més positives. Pel que fa al Secretum, l'oraculum s'extén a tota l'obra. En el cas del Curial e Güelfa em referesc, en concret, a l'episodi que va estar batejat per Lola Badia (1987, 265-292) com a "segona visió mitològica de Curial" (III, 174-179) i que esdevé l'objecte d'aquest treball interpretatiu.

D'una banda, llegim al Secretum (Petrarca 1992), diàleg de caràcter ascètic i introspectiu, que Sant Agustí li retrau al poeta d'Arezzo el seu desig de

\footnotetext{
${ }^{\prime}$ En les referències successives a l'obra que apareixen en aquest treball em limitaré a constatar entre parèntesi el volum en números romans, seguit de la pàgina i de la línia corresponent en xifres aràbigues. El passatge al qual es refereix el present treball es troba a III, 174-179.
} 
glòria, el pecat de l'accídia i la sensualitat del seu amor per Laura, tot proposant-li no que anul-le la seua naturalesa humana, sinó que li pose fre dedicantse a una vida centrada en la contemplació, en la renúncia als béns terrenals i en l'intent d'aconseguir la perfecció interior que el duga pel camí de la saviesa.

Paradoxalment, però, l'anònim, que segons tots els indicis no dominava massa bé l'antigor clàssica ${ }^{2}$, es permeté el luxe d'anar més lluny, triant, com a figura venerable, com a al-legoria de la ciència, el déu Bacus, identificació que, d'altra banda, ha estat considerada estranya, i no sense motius, perquè el nostre anònim, en fer de Bacus el patró de les set Arts Liberals, li usurpa el lloc a Mercuri, a qui li correspon l'honor des del temps de Marcià Capel-la.

El que per a Lola Badia $(1987,275-276)^{3}$ és una confusió evident entre Bacus i Mercuri i li fa concloure que l'anònim ha identificat Bacus amb la Filosofia, podria justificar-se també des d'altres paràmetres: des d'una anàlisi contrastada entre el Bacus petrarquesc i el del Curial, des de la consideració de la possible estructura circular de la nostra novel-la cavalleresca i des de la constatació que la identificació Bacus-Filosofia no ha estat patrimoni exclusiu del nostre anònim sinó que, en altres textos gairebé coetanis, l'atribut iconogràfic que de bell antuvi acompanyà l'al-legoria de Bacus, és a dir el vi, va carregarse d'uns continguts semàntics que farien viable semblant identificació.

D'entrada, però, Petrarca. El poeta d'Arezzo, en adonar-se que acumular glòria i riquesa no ho era tot en la seua vida, evoca les figures d'Apol.ló i de Bacus i l'adoració de què foren objecte entre els poetes antics, sospitant quina va ser la raó per la qual els escriptors:

geminum Parnassi collem duobus iis dedicasse/.../, sed ut ab Apolline, quem deum ingenii vocabant, internum animi presidium, a Bacho autem rerum externarum sufficientiam implorarent (Petrarca 1992, 162) ${ }^{4}$.

No és l'objecte d'aquest treball, inicialment, averiguar si l'anònim ha identificat el seu Apol·ló, "déu de sapiència" (III, 72, 24-25), amb el petrarquesc, encara que tots hem llegit que aquest déu li dóna enginy a Curial en el Parnàs perquè decidesca quina és la paraula poètica "veritable" (III, 90), a més de protecció interior, de l'ànim, per enfrontar-se estoicament al captiveri que patirà tot seguit a Tunis (III, 98 i ss). Tot i això, haurem de reprendre aquest discurs més endavant.

El que ens interessa de debò és trobar correspondències entre el Bacus de l'anònim, "déu llur de sciència" (III, 72, 24-25) i el petrarquesc, déu de sufi-

2 Lola Badia (1987, 292) opina que l'anònim incorre sovint en la confusió en les reconstruccions mitològiques.

${ }^{3}$ Lola Badia hi arriba a la conclusió que l'anònim proposa, mitjançant la figura de Bacus, una moral laica i moderna, basada en la virtut i a mig camí entre el menyspreu del món que li proposa Sanglier a Curial en començar el pelegrinatge del tercer llibre (III, 37-44) i l'heretgia epicúria a què es lliura el nostre protagonista una vegada que recupera la llibertat (III, 173).

${ }^{4}$ La cursiva és meua. 
ciència dels béns exteriors ${ }^{5}$, així que, convençuts de la coherència estructural del Curial e Güelfa, hem girat els ulls envers el llibre primer, més concretament envers el passatge en què hom li reconeix a Curial per primera vegada aptituds científiques i en què, a més, les Arts Liberals del Trivium i la filosofia també hi fan acte de presència. Vegem-ho tot seguit.

Curial assoleix en el llibre primer, i per aquest ordre, la ciència i el prestigi $\mathrm{i}$, de retruc, l'amor i la solvència econòmica després del "temps de la desfavor" (I, 26, 8-9): en adonar-se que el Marqués de Monferrat ha deixat d'afavorir-lo per menar-lo en l'oblit, "per no perdre el temps" (I, 26,9), decideix de fer-se un home de seny i, dedicant-se a la vigília de l'estudi, aprèn gramàtica, lògica i retòrica, és a dir les matèries del Trivium i, a més, filosofia. Aquest aprenentatge, a través del qual desenvolupa lliurement les seues qualitats i capacitats sense dependre de ningú, el farà famós com a poeta ("e fonch valent home en aquestes sciències, e axí mateix poeta molt gran"; I, 26, 10-12), a banda de proporcionar-li "en moltes partides, sabent-se la sua sciència" (I, 26, 12-13) la consideració de tothom. I el que és més important, li permetrà d'aconseguir, de retruc, que Güelfa s'enamore d'ell i el faça partícep de la seua solvència econòmica $(\mathrm{I}, 28,10-15)$.

La ciència adquirida per mitjà de l'estudi del Trivium i de la filosofia esdevé, doncs, el primer tresor del nostre Curial, l'instrument mitjançant el qual aconsegueix béns exteriors, amorosos i econòmics, els quals deuen ser, si fa no $\mathrm{fa}$, aquells que, segons Petrarca, desitjaven els poetes de l'antigor clàssica que s'encomanaven al déu Bacus.

Si avancem ara fins al llibre tercer, més concretament fins a la Visió de Curial (III, 174-179), comprovem que el nostre protagonista ha tornat al temps de la desfavor, però també al de la reflexió i al de la reacció: després de vanagloriar-se de l'amor d'una Güelfa que se l'estima amb dificultat i d'haver-se lliurat als convits, a les festes i a la lascívia venusina (III, 173, 16-18), després de rebre l'amonestació de Bacus, qui, acompanyat de les set Arts Liberals, li aconsella que gire els ulls envers aquelles que l'havien llicenciat, reflexiona sobre el sentit d'aquesta visió $\mathrm{i}$, tot reconeixent la inoperància de la seua darrera etapa vital, torna a la vigília de l'estudi, "tenint per perdut aquell temps que sens studi havia viscut" (III, 179, 11-12).

Curial, a hores d'ara, ja és ric gràcies al tresor de Camar. Tanmateix, encara ha de recuperar-se moralment, encara ha de retrobar-se amb aquella manera lícita que tenia de guanyar-se el pa, amb el modus vivendi que l'havia fet progressar en el llibre primer, abans fins i tot de conèixer Guielfa i de gaudir dels seus diners, i que no és altre que reconèixer que, tornant a l'estudi i a l'exercici de la poesia, el prestigi quedava assegurat.

Així, doncs, el discurs ètic de Bacus és ben clar: en el "temps de la desfavor" cal que Curial es deixe de plagasitats i es dedique a fer allò que l'havia fet

${ }^{5}$ La traducció és meua. 
prosperar en el primer llibre, a saber: conrear el Trivium i la filosofia per tal de ser "poeta molt gran" (I, 26, 12). És aquest el camí mitjançant el qual recuperarà l'estima social, la solvència econòmica $\mathrm{i}$, si vol, aconseguirà novament resultats satisfactoris en matèria amorosa. Qualsevol altra manera de viure serà, segons el fil narratiu, perdre el temps.

Així les coses, creiem que l'anònim podria haver entès, si és que va llegir el Secretum, que si el seu Curial, com els poetes antics, es deixava aconsellar i prestava servei al Bacus de Petrarca, un déu subministrador de béns exteriors, recuperaria tot allò que en el llibre primer havia aconseguit. Fet i fet, fa que Curial rebutge les pràctiques conductuals que havien enlletgit la seua personalitat i que l'havien conduit a la davallada moral, i el fa tornar a la vigília de l'estudi, la qual cosa, com ja sabem, li reporta els béns exteriors que havia perdut. Això, no obstant, amb escreix: el prestigi, l'amor i el perdó de Güelfa i, a més, el principat d'Orange.

Som davant d'una manera d'entendre el Bacus petrarquesc? D'entendre la vida? Del que no hi ha dubte és que, si la "filosofia" del llibre primer i Bacus són la mateixa cosa, som davant d'una actitud vital obertament pragmàtica que sap que l'estudi i la recerca de "libres en totes les facultats" (III, 179, 9-10) permet l'exercici d'una poesia que allibera de l'oci i que compensa amb béns exteriors. Ara bé, la moral laica que es desprèn d'aquesta actitud, per molt que vulga defugir el menyspreu del món, encara té una bona dosi de moral cristiana, ja que de cap manera permet les plagasitats.

A hores d'ara, doncs, i després d'altres treballs que justifiquen que Bacus, déu del vi, pot confondre's amb un déu sota el qual s'emparen les Arts Liberals (Badia 1987, 273-277 i Butiñà 1992, 264-266), no caldrien altres punts de vista. Tanmateix, i per acabar, volem afegir ací un parell de notes al respecte. D'una banda la constatació que, ja en temps de l'anònim, el contingut d'un llibre bo i filosòfic era comparable amb el vi. Vegeu, si més no, el que diu Alonso de Cartagena en el pròleg a la seua traducció del De senectute ciceronià (1422):

Por lo qual, asy como los vezinos e amigos suelen enviar a las vezes un pichel pequeño de vino de cuba furada, asy yo de la bodega de Cicerón vos enbío este pequeño pichel (Lawrance 1979, 16).

Podem pensar dues coses: que Cartagena establí un símil original entre el contingut d'un llibre filosòfic bo i el vi d'un bon barril o que aquesta era una imatge que corria aleshores entre els cercles de lletraferits, la qual cosa faria viable que Bacus fos l'al-legoria de la Filosofia que encapçala les Arts Liberals.

Pel que fa a Bacus, déu de ciència, volem dur a col-lació les paraules que J. M. González de Zárate escriví a propòsit del significat que s'amagava sota el déu Bacus en els gravats dels segles XV-XVII: 
Por Baco se entiende la mayoría de las ocasiones al dios del vino y del placer. Pero su figura llegó a referir aspectos importantes en estos siglos. Se le consideró el descubridor de la verdad, también padre del olvido. Cartari lo presenta como dios de la paz, de la justicia y del conocimiento (González 1991, 202).

\section{LA REINA GRAMÀTICA I EL CANTELL DE PA}

Passem a comentar tot seguit un altre element anòmal dels que apareixen a la segona visió mitològica. Em referesc al cantell de pa que la reina Gramàtica duu a la mà esquerra (III, 177).

Lola Badia $(1987,284)$ no troba cap altra justificació a aquest sorprenent atribut iconogràfic que la de simbolitzar el poder nutritiu d'aquesta disciplina primera, ja que no es troba documentat enlloc.

Amb tot, ja que en el capítol anterior hem recorregut a la coherència estructural de l'obra i a la confrontació amb d'altres textos literaris, hem optat per seguir pel mateix camí en aquesta part, per bé que, en lloc de confrontar novament la nostra novel.la amb un altre text petrarquesc, suggerim, per diversos motius, el següent fragment del pròleg a la quarta jornada del Decameron:

E molti, molto teneri della mia fama mostrandosi, dicono che io farei più saviamente a starmi con le Muse in Parnaso che con queste ciance mescolarmi tra voi [les dones]. E son di quegli ancora che, più dispettosamente che saviamente parlando, hanno detto che io farei più discretamente a pensar dond'io dovessi aver del pane che dietro a queste frasche andarmi pascendo di vento /.../. Certo io non so, se non che, volendo meco pensare qual sarebbe la loro risposta se io per bisogno loro en dimandassi, m'avviso che direbbono: 'Va cercane tra le favo$l e^{\prime 6}$. E già più en trovarono tra le favole i poeti, che molti ricchi tra' lor tesori." (Boccaccio 1980, 336 i 341).

Hi ha raons per a creure que no anem desencaminats si considerem vàlida aquesta manipulació del text boccaccesc. Per començar, recordem que Aramon i Serra (Curial, III, 260) ja havia fet notar que les consideracions a què es lliura Güelfa en quedar vídua del duc de Milà (I, 26-27) no eren altra cosa que un manlleu a les paraules emeses per Guismonda, la protagonista de la primera novel-la de la quarta jornada del Decameron, i el text que ací presentem no es troba gaire lluny de la paràfrasi detectada ja fa anys.

De més a més, tant l'amonestació com l'exhortació corren per la mateixa drecera en els dos textos: d'una banda, els malintencionats del Decameron i

'Les cursives són meues. 
Bacus al Curial e Güelfa increpen l'ociós certaldès i el també ociós i luxuriós Curial a causa del seu comportament llicenciós; d'altra, hom exhorta de manera semblant a l'estudi. Resulta viable, doncs, identificar el "cercane tra le favole" del Decameron amb allò que ja hem dit que fa Curial en despertar-se, és a dir, "cercar libres en totes les facultats" (III, 179, 9-10).

Cal entendre per favole aquelles composicions creades sota la protecció de les Muses del Parnàs, en llengua si més no llatina, en vers i amb un estil sublim, contraposades - com llegim al Decameron - al gènere, llengua i estil en què Boccaccio i el nostre anònim escriuen respectivament les obres que confrontem, és a dir, narracions "en volgare e in prosa /.../ senza titolo, ma ancora in istilo umilissimo" (Boccaccio 1980, 335) i dedicades ambdues, de més a més, a les dones? ${ }^{7}$. Així doncs, favola o faula vol dir, si fa o no fa, poesia feta a la manera dels clàssics.

Ara bé, si els mots favole i libres han estat posats en un mateix nivell significatiu i anar rere les favole comporta exercir de poeta a la manera dels clàssics per guanyar-se dignament el pa, ¿no haurà volgut indicar-nos l'anònim amb la fantasia iconogràfica del cantell de pa que el seu Curial, per a recuperar la solidesa moral i tornar a la poesia, haurà d'anar rere la Gramàtica? Haurem d'entendre que Gramàtica i poesia són, per a l'anònim, la mateixa cosa 0 , si més no, que el tipus de llibres que el seu protagonista escorcollava en el passat eren, per força, gramaticals i són els que li valgueren el títol de poeta? ${ }^{8}$

Anem, però, per parts. Sabem que Curial, en "el temps de la desfavor", assolí prestigi i esdevingué "poeta molt gran" (I, 26, 12). El cas és que això va ocórrer abans de conèixer la Güelfa i de fer-se trobador:

e, lexada a un depart la altra manera que tenir solia, si bé se era bona, tornà molt prudent $\mathrm{e}$ abte; car tantost fonch molt bell cantador, e après sonar esturments (de què devench molt famós), axí mateix cavalcar, trobar $^{9}$, dançar, júnyer e totes altres abteses que a noble jove e valerós se pertanyia" (I, 30, 16-23).

En els segles XII i XIII, el mot poeta quedava reservat per a qui versificava en llatí culte (Riquer 1983, I, 19). De més a més, Lola Badia $(1988,152)$ ja va apuntar que, entre els escriptors del segle XV de la corda de Sant Vicent Ferrer o de Jaume Roig, el llenguatge versificat dels trobadors era una cosa ben

\footnotetext{
${ }^{7}$ L'anònim diu que al tercer llibre hi ha "poètiques ficcions, scrites no en la manera que a la matèria se pertany, mas axí rudament e grossera". El Curial, de més a més, apareix sense títol, en vulgar i en prosa, i dedicat, com el Decameron, a les dones: "a vostra consolació e plaer" (I, 55, 10), "di piacervi e di consolarvi" (Boccaccio 1980, 335).

${ }^{8}$ Recorde haver llegit que el blat era sinònim de poesia per a escriptors com Geoffrey Chaucer. De més a més, no hem d'oblidar que el llibre III del Curial s'obri amb el record de la disputa poètica que mantenen, a les Metamorfosis ovidianes, les Muses contra les seues germanes les Pièrides (V, vv. 295-678), el triomf de la qual correspongué a la representant de les Muses, Cal-líope, per haver recitat la faula del rapte de Proserpina, filla de Ceres, deessa del blat i de les collites.

${ }^{9}$ La cursiva és meua.
} 
diferent a la "poesia", entesa aquesta darrera com a producció dels clàssics i dels moderns Dante i Boccaccio.

A hores d'ara tot faria suposar que, certament, el nostre anònim, mitjançant Bacus, anima Curial perquè torne a ser poeta a la manera dels antics, ja que l'única faceta creativa que coneixem de Curial, la composició trobadoresca occitana Atressí com l'aurifany, queda exclosa d'allò que l'anònim entenia per "poesia". No debades, quan ens presenta el seu protagonista com a autor d'aquesta peça trobadoresca, no utilitza la fórmula "poeta molt gran" del llibre primer, sinó que escriu "com aquell qui era gran trobador" (III, 148, 5).

Amb tot, si no hi ha cap mostra arreu la novel-la d'un Curial que haja versificat en llatí culte, com és que ha estat considerat poeta? Ens fa l'efecte que haurem de cercar la resposta en el nom de les donzelles que acompanyen la reina Gramàtica $i$ en la nòmina de savis que la serveixen ${ }^{10}$. Per aquesta via observem que entre la llista de gramàtics figura el nom d'Alexandre Villa-Dei, autor d'una gramàtica elemental de gran difusió en l' Edat Mitjana, molt criticada pels humanistes: el Doctrinale (III, 177, 6).

Aquest gramàtic dividia l'estudi de la disciplina en Ortographia, Etymologia, Dyasintastica i Prosodia (Marcos Marín 1975, 132), submatèries que es corresponen amb el nom de les donzelles amb rètol que acompanyen la reina Gramàtica (III, 174, 23-24). De més a més, Villa-Dei considerava que la gramàtica era, en realitat, l'essència de la poesia $\mathrm{i}$ el fonament de les altres ciències, no sols perquè monopolitzava l'art verbal -especialment, l'estudi de les exornationes (flores i colores rhetorici) - , sinó també perquè mantenia les seues antigues competències, entre elles l'exercici clàssic de la enarratio poetarum, és a dir, l'anàlisi i interpretació de les obres literàries. La gramàtica del cantell de pa és, doncs,

logicae ministra, rhetoricae magistra, theologiae interpres, medicinae refrigerium et totius quadrivii laudabile fundamentum (Bice Mortara 1991, 50).

Fet i fet, "ser poeta" no deu ser per al nostre anònim únicament escriure a la manera dels antics, ans també conrear, interpretar i valorar les faules poètiques de factura clàssica, en vers i en llatí. És per això que, encara que no tenim en Curial un poeta en el sentit estricte, sí que el podem considerar exegeta, lector, estudiós i jutge dels clàssics, com es pot deduir de la seua estada al Parnàs i de les seues converses amb Camar a Tunis.

Així, doncs, la prima arte Gramàtica ${ }^{11}$ nodreix les altres ciències i esdevé l'eina bàsica amb què interpretar, valorar i conrear la poesia. De més a més, en

\footnotetext{
${ }^{10}$ Recordem que l'anònim, amb tota la intenció del món o per ignorància, s'encarrega d'estalviarnos la llista de savis adscrits a les altres disciplines liberals, la qual cosa dóna un relleu insospitat i una bona càrrega significativa a la presència exclusiva dels gramàtics.

${ }^{11}$ Recordem, de més a més, les paraules de Dante en el De Vulgari Eloquentia II, iv (1988, 104): "Differunt [qui vulgariter versificantur] tamen a magnis poetis, hoc est regularibus, quia magni
} 
la lectura d'aquests "libres" científics, Curial pot trobar, com Boccaccio en les seues faules, més riquesa que els rics entre els seus tresors. No debades Bacus diu a Curial: "Sies cert que no 't aprofitarà tant lo thesor de Camar com te nourà la teua desconexença e ingratitut"(III, 179, 2-4).

Curial, doncs, ha de retrobar-se ${ }^{12}$ per a vèncer la supèrbia i la vanaglòria. Tanmateix, quina riquesa pot descobrir en llibres gramaticals? Com ja és ben sabut, un dels llibres de capçalera de l'anònim va estar la Historia destructionis Troiae ${ }^{13}$, del protonotari sicilià Guido delle Colonne. En aquest llibre trobem la següent recomanació: "qui gramaticam legunt, $u t$ separare sciant uerum a falso ${ }^{14}$ de hiis que de dicta ystoria in libris gramaticalibus sunt descripta, ea que per Dytem Grecum et Frigium Daretem..." $(1936,4)$.

Comptat i debatut, si l'anònim recordava encara les paraules d'aquest mestre seu, no sols deu estar incitant Curial perquè continue llegint llibres de gramàtica que l'ajuden a triar sempre, com a paraula poètica "veritable", les contalles de Dictis i Dares en detriment de la versió homèrica, per considerarla falsa, sinó que també ha tornat a atacar els clàssics que fingeixen coses que no foren veritat en el fil de la història $i$ a fer una defensa sense escletxes de les seues idees literàries, exposades al començament del llibre tercer i en el somni del Parnàs, i posades en boca del déu Apol-ló: "Bo és poetar, mas, contra veritat escriure no'm par sie loor" (III, 89, 21-22) ${ }^{15}$. Cercar llibres gramaticals per totes les facultats proporciona, doncs, el millor tresor: la possibilitat de trobar la "veritat".

sermone et arte regulari poetati sunt". L'edició, a cura de Sergio Cecchin, explica en pàg. 105, nota 10 que els poetes "regulars" són, òbviament, els clàssics, els quals se serviren de la "gramàtica" a l'hora de fer les seues composicions. Les característiques principals d'aquesta art són la seua convencionalitat i el fet d'ésser regulada per normes invariables. Dante, que identifica Gramàtica amb llatí (Cfr. I, i; I, x; I, xi i II, viii), considera que els rimadors o poetes en vulgar que inventen composicions servint-se únicament de la retòrica i de la música han d'emular els poetes regulars per tal de donar prestigi a la poesia en vulgar.

${ }^{12}$ No sols Bacus li recomana a Curial que es lliure de la seua desconeixença; també l'anònim, amb un exemple inclòs en el pròleg al llibre tercer:'Recognosce te ipsum ne te extollas" (III, 11, 5-6). Aramon i Serra (Curial 1933, III, 270) ens suggereix confrontar aquesta cita amb el Breviloqui de Joan de Gal.les. Potser ens interesaria també dur a col.lació les paraules de Petrarca a Familiares, II, ix: “...y, contra el precepto de Apolo ('conócete a tí mismo") nos esforzamos con afán en desconocernos a nosotros mismos" (Petrarca 1978, 1, 248).

${ }^{13}$ Cal recordar que aquesta obra era molt coneguda a la Corona d'Aragó, ja que n'hi havia una traducció al català feta per Jaume Conesa, editada per Miquel i Planas el 1916. Aquesta traducció seria coneguda, sens dubte, tant per l'autor del Tirant com pel nostre anònim.

${ }^{14}$ La cursiva és meua.

15 Llegiu, en aquest sentit, els treballs de Lola Badia (1988, 121-144) i de Jaume Turró (1991, 149-168). Turró detectà una possible influència petrarquesca en el capítol en què l'anònim denuncia que Virgili alterà la veritat històrica en fer coetanis Eneas i Dido, morta aquesta tres segles abans (III, 89). Al seu torn, Lola Badia assenyala que, segons la tradició patrística, Dido és un heroic exemple de sacrifici per la fidelitat conjugal i que Virgili, amb les seues poètiques ficcions enllorda el perfil de l'heroïna, la qual cosa indigna l'anònim. Aleshores, podem concloure que l'anònim no reprova tant que els clàssics transgredesquen la veritat històrica com la veritat moral de la història. 


\section{EL CANTAR DE RETÒRICA}

Pot ser que, de tots els elements iconogràfics de la segona visió, el cantar que executa la reina Retòrica siga el més conflictiu, per tal com apareix en altres episodis i perquè, de fet, és el que ens ha dut pels paranys més perillosos ja que aquesta activitat gaudia de molts detractors. Això no obstant, treballarem el sentit d'aquest mot confrontant-lo, novament, amb l'educació de Curial i deixant per a una altra ocasió el significat que pot tenir en altres parts de la novel-la.

Hem dit més amunt que Curial ja havia guanyat prestigi com a poeta quan coneix Güelfa. Aquesta li proporciona una situació benestant gràcies a la qual pot afegir al seu procés educatiu tot un seguit d'activitats plaents circumscrites a l'òrbita de l'estament aristocràtic.

En efecte, el nostre protagonista, deixant a part els seus costums literaris i científics inicials, s'endinsa en un ambient cortesà, delitós i ociós en què no sols descobreix la disciplina militar, sinó que també esdevé trobador de cançons líriques, amb tot el que aquests termes impliquen, a saber: compondre lletres de temàtica essencialment amorosa en occità, casar-les amb la mùsica $i$ cantar-ne les composicions. En altres paraules, des que es veu afavorit, subordina la fama que li havia donat l'estudi, el conreu i la interpretació de la poesia llatina a la fama curialesca que aconsegueix com a cavaller i com a trobador-cantor de temes amorosos en llengua neollatina.

Això no vol dir que deixe definitivament l'estudi, com fa en el llibre tercer abans d'ésser amonestat per Bacus, ja que en el llibre segon el rei de França encara li dedica el seguient elogi:

car és tant diligent que no pert el temps /.../ si'l volets en cambra cantar, dançar e solaçar curialment /.../e partit d'aquí no lexa l'estudi (III, $253,6-12$ ).

El que fa en el llibre segon no és, doncs, perdre el temps totalment - almenys així ho creu el màxim representant de l'àmbit cortesà - sinó, segurament, traslladar els seus interessos literaris a un altre port: el trobadoresc.

L'art dels trobadors reprodueix, segons Riquer (1983, I, 73) els ensenyaments que aquests havien après a les escoles monàstiques, $i$ una part del seu quefer poètic no era altra cosa que un trasllat a la llengua vulgar de les teories sobre composició llatina que havien estudiat en els tractats de retòrica. Així trobem amb frequiència expressions com colorar un chan, polir un chan, passar la lima, que es comesponien amb les llatines colores rethorici, polita, inventio perpolita.

Ens preguntem si el fet que Curial afegesca l'educació trobadoresca al seu currículum pot ser una de les raons per les quals la reina Retòrica apareix amb "un cartell scrit e notat a nota de cant, en lo qual mirava contínuament, e ab una ploma esmenava" (III, 175, 15-18). 
El símbol d'una retòrica que canta podria tenir així un cert sentit. Tanmateix, no deixa de sorprendre'ns l'aparició d'aquest motiu, perquè una cosa és que Retòrica es mostre "de vàries colors vestida" (III, 175, 13) com mana la tradició i, fins i tot, polint i corregint el paper pautat, i altra de molt diferent, però, és que execute musicalment amb la veu, com un trobador qualsevol o el seu delegat, el joglar líric, la composició, ja que la temptativa de passar revista a la valoració que la nostra tradició literària dóna a l'educació artística i cortesana de Curial —cantar, sonar instruments, trobar i dançar- ens revela que l'opinió generalitzada no li és gens favorable.

Fem un repàs, doncs, ais sentiments que despertaren aquestes activitats al llarg de la nostra literatura, detenint-nos, per a començar, en les opinions de Ramon Llull. El nostre beat, en el Llibre de contemplació en Déu, veia en el conreu d'aquesta literatura profana una desviació del que havia estat, en un començament, la primera intenció de la poesia, és a dir, lloar i beneir Déu. Un déu que, si per dignitat era veritat, les composicions que a ell se li dedicaren haurien de ser-ho també:

car los hòmens qui s'entremeten de sonar estruments e de ballar e de trobar, no canten ni no sonen los estruments, ni no fan verses ni cançons sinó de luxúria e de vanitats d'aquest món/.../. Aquells, Sényer, qui sonen los estruments e qui canten de putaria e qui loen cantant aquelles coses qui no són dignes d'ésser loades, aquells són maleïts (Bonner-Badia 1991, 99) ${ }^{16}$.

Francesc Eiximenis també avorreix aquestes activitats i fa una invectiva contra els cavallers que "no viuen virilment sinó com a fembres i a causa de les males fembres, van per carrers i places cantant ${ }^{17}$ cançonetes vils." (Hauf, 1995, 2).

Trobem un altre testimoni semblant en un miracle de l'homilètica vicentina:

Llegim que en una ciutat ere hun bell jove /.../ contínuament entenie en burleries, anar a bordells, anar a sonar, dançar, etc. E una nit somnià que vehie Jesucrist en la cadira, e lo juhí de les ànimes /.../ e Déus dix-li: 'Redde rationem villicationes tue'; de què se espantà $/ . . . /$ e mudà tantost la vida, lexà les grans cotes e pres cilici, etc. (Ferrer 1975, III, 12).

Això ens duu, per lògica, a plantejar-nos diverses possibilitats: o que l'anònim justifica $\mathrm{i}$ accepta sense reticències els nous coneixements de Curial - com ho fa el rei de França-, la qual cosa faria del Curial e Güelfa una novel-la que reivindica uns postulats oposats a la tradició dels moralistes, o que opina el mateix. Fins i tot, podríem pensar que pretén harmonitzar els dos extrems.

\footnotetext{
is La cursiva és meua.

${ }^{17}$ La cursiva és meua.
} 
Ens fa l'efecte, però, que cal inclinar-se per la segona possibilitat, ja que, si ja ha estat estudiat que sota enunciats literaris l'autor articula una lliçó moral segons la qual certes conductes no són adients al cavaller, perquè poden fer-lo caure en el vici de la supèrbia ${ }^{18}$, segur que tampoc certes pràctiques artístiques i cortesanes de les apreses per Curial -entre elles el "cantar"- ho seran, ja que, a més d'haver-les après simultàniament a les cavalleresques que el conduïren a l'ensorrada moral, quan compon i canta temes vinculats a l'amor profà, el protagonista no sols corre el risc de caure en els vicis de la vanaglòria i la luxúria, sinó que, de fet, hi cau.

Així, doncs, si Curial canta composicions trobadoresques neollatines de temàtica amorosa modulant melodiosament la veu, deu estar allunyant-se de Déu i, en consequiència, de la veritat. En aquest cas, no convé que el nostre cavaller practique aquesta activitat que l'anònim ha vinculat a la retòrica, perquè es troba, de retruc, íntimament lligada a la luxúria venusina.

Així les coses, proposem llegir el que passa abans de l'amonestació de Bacus. En efecte, en aquest episodi Curial recrea els comportaments que rebutjaven els moralistes, ja que repeteix momentàniament els clixés pels quals li havia vingut la davallada moral i intel-lectual:

ans axí la disciplina militar, com la vigília del studi, mès totalment en oblit e en menjars, convits e festes, vestirs e altres vanitats, $\mathrm{e}$ ' $\mathrm{n}$ los actes de Venus, despenia totalment lo temps (III, 173, 14-18).

En aquestes festes, tot fa suposar que el nostre protagonista continuava practicant el cantar, el sonar i el dansar, la tòpica tríada verbal ${ }^{19}$ que tanta animadversió havia provocat entre els nostres escriptors.

A hores d'ara haurem de pensar que ja en el rerefons mental de l'autor, quan diu en el llibre primer que Curial, "lexada a un depart la altra manera que tenir solia, si bé se era bona" esdevingué gràcies a l'amor i als diners de Güelfa "molt bell cantador, e après sonar esturments/.../cavalcar, trobar, dançar, júnyer"(I, 31, 16-21), va establir-se una estreta relació entre les armes i l'amor, entre la inoperància lasciva i festiva de la cavalleria (cavalcar, júnyer i errar) que condueix al vici de la supèrbia i la pràctica de la ciència musical trobadoresca, és a dir la gaya ciència, activitat aquesta darrera, tot i que basada en la retòrica llatina, també plaent i ociosa, ja que la seua finalitat essencial consisteix a elogiar les dones mitjançant el cant plaent. Com ja hem vist més amunt, l'anònim, a través de Bacus, no permet la frivolitat, ans bé insisteix que Curial abandone aquestes plagasitats cortesanes i cerque el coneixement en les facultats.

Si encara no tenim prou amb l'evidència que el cantar trobadoresc no tenia bona premsa entre els moralistes, o amb el pressentiment que l'anònim es mos-

\footnotetext{
${ }^{18}$ En aquest sentit vegeu la nota 21.

${ }^{19}$ Aquesta expressió esdevingué un lloc comú des del temps dels trobadors. Llegiu, en aquest sentit, algunes de les vidas compilades per Martí de Riquer 1983, I-III.
} 
tra reticent als nous estudis del seu protagonista, recordem quina és la reacció de Güelfa en l'episodi en què el Marqués anima uns captaires -que no són altres que Curial i el seu company disfressats- perquè canten davant la seua germana, la qual es troba malalta (III, 164-167).

Quan Güelfa sent cantar la cançó de l'aurifany als dos joves indigents que han vingut a donar-li conhort, sospita que un d'aquells pot ser el seu estimat Curial, ja que la lletra s'ajusta a la condició que ella havia posat quan el rebutjà definitivament a causa de la seua infidelitat en acabar el llibre segon (II, 286-287). No satisfeta, i després de fer-los cantar per tres vegades la mateixa cançó, mana a Curial que la recite novament, tot i que aquesta vegada sense interpretació musical, és a dir, "de paraula, sens cantar"(III, 167-6).

Aquesta petició, al meu parer gens gratuïta, ens fa pensar que el nostre anònim i, subsidiàriament, Güelfa consideren que l'execució musicada de la cançó trobadoresca és un vel retòric més que amaga la veritat i dificulta l'anagnorisi, com ho seran també la disfressa de Curial, el canvi de nom i pàtria i la llengua en què canta. Güelfa, sense execució musical de per mig, sembla sentir-se capaç de trobar una remor que li resulta verídica i familiar, bé en la modulació de la veu de Curial, bé en la seua sinceritat interpretativa a l'hora de recrear la clàusula que ella mateixa havia disposada per tal de perdonar-lo.

Aquesta manera d'obrar de Güelfa, proscriure la música que se superposa a una lletra i permetre l'assumpte recitat, sembla respondre a l'animadversió generalitzada dels nostres autors envers els trobadors i la manera retòrica que tenien de colorar la peça amorosa neollatina: la cançó a la qual s'afegeixen instruments i melodia vocal ${ }^{20}$.

Per aquest camí hem de considerar que la peça trobadoresca de contingut amorós, cantada, no exerceix cap influència sobre el cor de la senyora, no té poder catàrtic ni persuasiu, ans esdevé un entrebanc, un color retòric més que dificulta la reconciliació dels protagonistes. Güelfa, de fet, de qui va enamorarse va ser del Curial-poeta de "lo temps de la desfavor", no pas del cavaller-tro-

\footnotetext{
${ }^{20}$ No és, però, la primera vegada que l'anònim demana que hom no cante, ja que també fa callar els homes pobres de ciència que segueixen les Pièrides, les quals ni sonen ni canten tan bé com les seues germanes les Muses ( III, 7 ). Igualment es demana silenci ell mateix: "elegesch callar" (III, $13,4)$. Amb tot, el silenci que es demana només deu proscriure la veu musical, ja que continua escrivint, de paraula, sense cantar, les peripècies del seu Curial. Això sí, en fugir de la vana dolçor del cant i de la construcció rítmica, a l'anònim li queda la possibilitat de conrear un altre gènere: la prosa. Així doncs, ens fa l'efecte que l'anònim distingeix entre el cant poètic en llatí -en què la melodia va implícita en els peus mètrics- $\mathrm{i}$ el cantar líric occità, el qual s'ha d'ajudar no sols del vel de la modulació vocal, sinó també del vel de la música instrumental, per tal d'esdevenir un tot compacte. I Curial, pel fet de ser "poeta molt gran", ha d'abandonar les pràctiques trobadoresques, ja que només li és permés dedicar-se als cants poètics en llatí que amaguen alguna lliçó moral. A hores d'ara em trobe treballant en un estudi que pretén dur per títol A la recerca del cantar $i$ el sonar de les Pièrides.
} 
bador en què es transformà el seu estimat, una vegada que caigué sota l'influx de la parella planetària i olímpica Mart-Venus.

Vénen ganes de pensar que si l'autor, en l'intent d'establir un ordre de significats "científics" que lligaren l'exercici de les armes -o, més ben dit, dels seus vicis- ${ }^{21}$ amb el planeta Mart va recórrer a autoritats com Macrobi i Dante (Badia 1988, 127-129), no seria gens estrany que, per tal de justificar la davallada intel-lectual de Curial (de poeta llatí a trobador occità) susbsidiària de la cavalleresca, s'hagués aprofitat novament d'altres referents literaris, de manera que l'ofici de trobador i el seu cantar quedaren vinculats als vicis a què condueix Venus, és a dir, a la ingratitud i a la luxúria.

Per a aquesta hipòtesi no podem trobar altra eixida que la de la possible manipulació i hibridació de textos abans de la redacció. Admetre que "cantar" és per a l'anònim un color retòric més que els trobadors afegiren a la disciplina retòrica, ens facilitaria les coses. També recordar la invectiva dels nostres moralistes contra els que canten i sonen peces de contingut amorós, és a dir, els trobadors.

Així, doncs, volem oferir com a proposta de lectura la següent hipòtesi: si des de Martianus Capella (Murphy 1986, 50) la retòrica havia estat representada amb els atributs que caracteritzen Mart ${ }^{22}$, és a dir, amb les armes i ferint defensant-se dels seus adversaris, i Dante (1990, 110-111), en el segon capítol del Convivio, compara la retòrica amb el planeta Venus i a la música amb el planeta Mart ${ }^{23}$, ens fa l'efecte que l'anònim està treballant sobre un joc creuat d'idees segons el qual el nostre protagonista, quan es dedica al conreu dels vels retòrics pot caure en els vicis de la parella olímpica Mart-Venus, la qual cosa pot entendre's, si fa no fa, amb el següent quadre sinòptic:

${ }^{21}$ Lola Badia apunta en el seu treball que l'anònim, en lligar l'exercici de les armes amb el planeta Mart per tal de justificar la supèrbia dels cavallers, no pretén blasmar la disciplina militar, sinó els seus vicis.

22 "Tocada con un yelmo y coronada con regia majestad, sostenía en una mano las armas con las que acostumbra a defenderse y a herir al adversario" (De nuptiis Philologiae et Mercurii, V, 425, apud. Murphy 1986,50 ).

23 "E lo cielo di Venere si può comparare a la Rettorica per due proprietadi: l'una sì è la chiarezza del suo aspetto, che è soavissima a vedere più che altra stella; l'altra sì è la sua apparenza, or da mane or da sera. E queste proprietadi sono ne la Rettorica: ché la Rettorica è soavissima di tutte le altre scienze, però che a ciò principalmente intende; e appare da mane, quando dinanzi al viso de l'auditore lo rettorico parla, appare da sera, cioè retro, quando da lettera, per la parte remota, si parla per lo rettorico/.../. E lo cielo di Marte si può comparare a la Musica per due proprietadi: l'una si è la sua più bella relazione, ché, annumerando li cieli mobili, da qualunque si comiencia o da l'infimo o dal sommo, esso cielo di Marte è lo quinto, esso è lo mezzo di tutti, cioè de li primi, de li secondi, de li terzi e de li quarti. L'altra si è che esso Marte, $/ . . . /$ dissecca e arde le cose, perché lo suo calore è simile a quello del fuoco; e questo è quello per che esso pare affocato di colore/.../. E queste due proprietadi sono ne la Musica, la quale è tutta relativa, sì come si vede ne le parole armonizzate e ne li canti, de "quali tanto più dolce armonia resulta, quanto piu la relazione è bella" (Dante 1990, 110 111). 


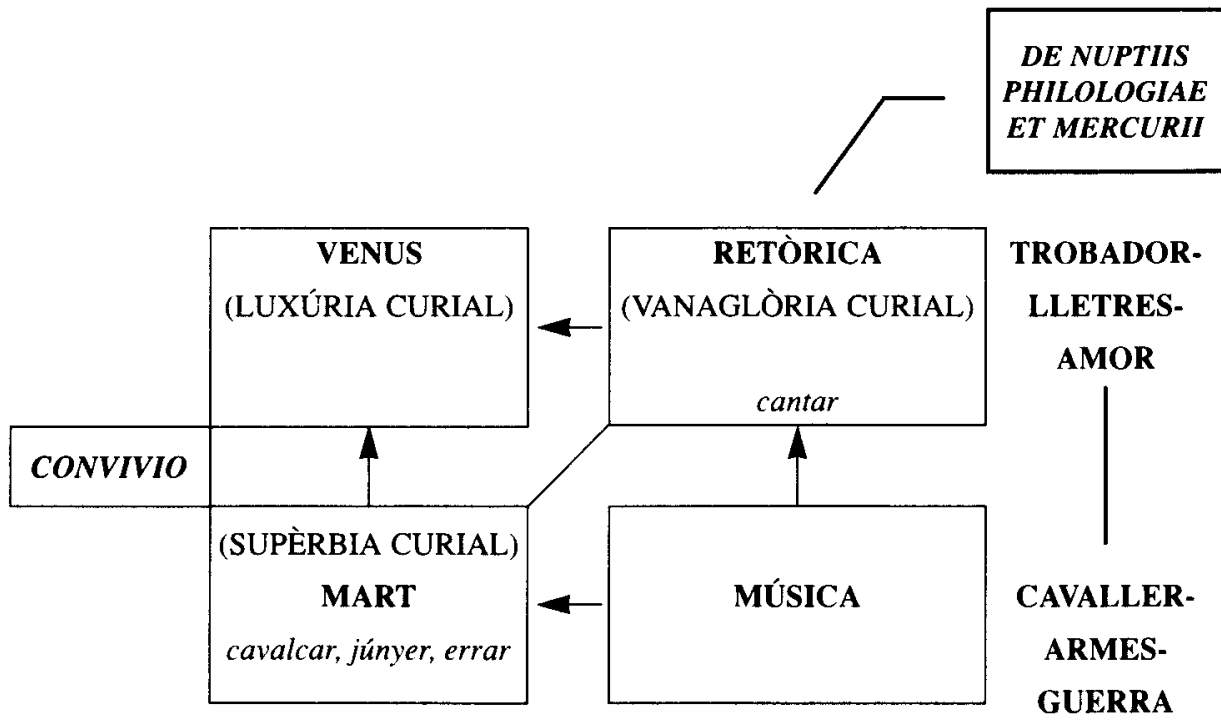

En efecte, per mitjà de l'associació d'idees i l'osmosi d'autors, l'anònim faria que el cavaller i trobador Curial hagués esdevingut superb a causa de Mart, vanagloriós a causa d'una de les disciplines de Bacus, la retòrica trobadoresca que, enorgullint-se del seu nou vel, el cantar, amaga veritat, i luxuriós a causa de Venus. Tanmateix, l'anònim no culpabilitza tant als planetes Mart $i$ Venus de la davallada de Curial com als vicis a què pot conduir-lo la seua educació cortesana: l'errar inoperant $\mathrm{i}$ el cantar trobadoresc, eixe vel retòric i musical de la ciència de Bacus, vinculat, segons els nostres moralistes, a la luxúria ${ }^{24}$.

${ }^{24}$ Curial s'estrena com a cavaller amb una defensa, la de la duquessa d'Àustria, i culmina la seua trajectòria amb la defensa de l'Imperi. La seua peripècia cavalleresca segueix, doncs, al començament i a l'acabament, el model de cavaller cristià definit per Ramon Llull en el Llibre de l'ordre de cavalleria. L'operativitat d'un cavaller consistia a defensar la fe i protegir els elements menys afavorits de la societat: vídues, orfes, etc. Aquesta pràctica no inclö̈a dedicar-se a la cavalleria errant, ni participar en torneigs per ferir sense una causa justificada. Els torneigs de la tardor medieval són una bona mostra de la davallada funcional de la cavalleria. Resulta, doncs, molt simptomàtic que la davallada moral de Curial tinga lloc en el llibre segon, precisament quan Curial no ha d'escometre grans empreses guerreres, quan l'única cosa que ha de fer és errar, demostrar la seua vàlua personal en els torneigs i protegir l'honor de Güelfa. Així, a banda d'acceptar que Curial esdevé superb a causa de Mart (cavalleria=supèrbia=música) haurem de considerar una ironia que a l'anònim li estranye que els autors catalans, en traduir els romans artúrics, mantingueren el terme "errar", en lloc de "caminar" quan per a ell té, de fet, una doble càrrega semàntica, a saber: vagar i equivocar-se. Si fa que Curial esdevinga superb a causa de Mart (II, 5-7) i, de més a més, pretén seguir en el llibre segon aquells que traduïren al català "los libres de Tristany e de Lançalot" (II, 7, 6-7), el que ens està dient, de fet, és que vol conduir el seu Curial cap a l'Infern dantesc, en què Tristany ocupa un lloc privilegiat pel pecat de la luxúria (Inf., V, 67). 


\section{CONCLUSIONS}

A l'hora de formular unes conclusions a tots els suggeriments que precedeixen, no ens trobem amb ciència suficient per a decidir si som davant d'un home lletraferit i pragmàtic que, enlluernat per la gramàtica tradicional, sabé aprofitar-se de Petrarca i de Boccaccio per tal de refermar-se en el seu anticlassicisme o si, per contra, des de paràmetres escolàstics d'allò més tradicionals, pretén aproximar-se al nou pensament dels humanistes.

Del que no hi ha dubte és que, si no hem anat errats en la nostra anàlisi iconògrafica i estructural, la divinitat apol-línia, la "ciència de la veritat" que s'escola pels llibres gramaticals i la poesia o, si més no, la valoració d'aquesta, han estat posades en un mateix nivell significatiu i supeditades, de més a més, al déu Bacus, al-legoria d'una actitud vital que reclama, per tal de poder assolir béns profitosos, l'estudi que evita l'oci.

Pel que fa a la nostra interpretació del cantar de retòrica, hem arribat a la conclusió que l'amputació profilàctica que practicà el Sant Ofici sobre la temàtica de la lírica trobadoresca, així com les idees sobre l'amor-hereos de factura galènica i la influència sobre la societat de la predicació amb objectius reformadors (Badia 1993, 147-150) no sols afectaren i modificaren la concepció del fet líric, sinó que també s'instal·laren, encara que subreptíciament, sota el discurs narratiu de factura cavalleresca i sentimental. És més, sembla que l'autor haja volgut deixar palesa una lectura moral segons la qual l'estil, les pràctiques retòriques i els temes dels trobadors traspassen, d'entrada, la llengua llatina en què tots els gramàtics que acompanyen Bacus poden entendre's i de més a més, sovint, la "veritat" i les virtuts corteses de la humilitat i de la modèstia a causa de l'escalf de Mart-Música i de Venus-Retòrica. Som, doncs, davant d'algú molt pròxim al pensament ausiasmarquià del poema XXIII? ${ }^{25}$. Pot ser que ambdós escriptors hagen exposat la mateixa idea?

Finalment, hem de reconéixer que, per traure l'entrellat d'aquests elements iconogràfics, no hem volgut desestimar la possibilitat que l'anònim es lliurés a hibridacions i manipulacions dels textos que pogué tenir a l'abast. Tanmateix, la intenció d'exposar subreptíciament idees ètiques i poètiques periclitades en un segle en què el món i les lletres es preparen per a rebre el nou continent actitudinal i literari italià, enriqueix la nostra novel-la amb l'ambigüitat amb què sempre ha estat caracteritzada la tardor medieval.

\section{REFERÈNCIES BIBLIOGRÀFIQUES}

Alighieri, Dante (1990), Convivio, ed. a cura de Piero Cudini, Garzanti Editore, cap. 2, XIII.

25 "Lexant a part l'estil dels trobadors / qui, per escalf, trespassen veritat" (March 1952, 83). 
- (1988), De vulgari eloquentia, ed. a cura de Sergio Cecchin, Milano, Tea.

BADIA, Lola (1987), "Segona visió mitològica de Curial: Notes per a una interpretació de l'anònim català del segle XV Curial e Güelfa", Estudis de Llengua i Literatura Catalanes, XIV (=Miscel-lània Antoni M. Badia i Margarit, 6), Barcelona, Publicacions de l'Abadia de Montserrat, pàgs. 265-292.

- (1988), De Bernat Metge a Joan Roís de Corella, Barcelona, Quaderns Crema.

- (1993), Tradició i Modernitat als segles XIV i XV. Estudis de cultura literària i lectures d'Ausiàs March, Institut Universitari de Filologia Valenciana-Publicacions de l'Abadia de Montserrat, València-Barcelona ("Biblioteca Sanchis Guarner").

Boccaccio, Giovanni (1980), Decameron, ed. a cura d'Antonio Enzo Quaglio, Aldo Garzanti Editore, Vol. I.

BONNER, Antoni -BADIA, Lola (1991 ), Ramon Llull. Vida, pensament i obra literària, Barcelona, Les Naus d'Empúries ("Pal Major", 2).

BuTiÑà, Júlia (1992), Boccaccio y Dante en el "Curial e Güelfa", Epos, Revista de Filologia. UNED, 7.

COLUMNIS, Guido de (1936), Historia destructionis Troiae, ed. a cura de Nathaniel E. Griffin, "The Mediaeval Academy of America", Cambridge, Massachussetts, pàg. 4.

CURIAL E GÜELFA, (1930-1933), 3 vols., ed. a cura de Ramon Aramon i Serra, Barcelona, Barcino ("ENC").

FERRER, Vicent (1975), Sermons, ed. a cura de Gret Shib, Barcelona, Barcino ("ENC", 6), Vol. III, LVI, pàg. 12.

GONZÁLEZ DE ZÁRATE, Jesús María (1991), Renacimiento y Barroco. Imágenes para la historia, Vitoria-Gastéiz, Instituto Municipal de Estudios Iconográficos EPHIALTE.

HAUF, Albert (1995), “¿Cristianisme versus classicisme? El messianisme profètic de l'època del Magnànim", Conferència pronunciada dins del curs L'època humanista a la Corona d'Aragó, Dénia, UNED, 12 de juliol del 1995.

LAWRANCE., Jeremy N. H. (1979), Un tratado de Alonso de Cartagena sobre la educación y los estudios literarios, Universidad Autónoma de Barcelona, pàg. 16.

LEWIS, C.S. (1985), The Discarded Image, Cambridge University Press.

MARCH, Ausiàs (1952), Poesies, 5 vols., ed. a cura de Pere Bohigas, Barcelona, Barcino ("ENC"), vol. II, pàg. 83.

MARCOS MARÍN, Francisco (1975), Lingüística y lengua española, Madrid, Cincel.

MORTARA, Bice (1991), Manual de Retórica, Madrid, Cátedra.

MURPHY, James J. (1986), La retórica en la Edad Media, México, FCE.

OVIDI NASó, (1929), Les Metamorfosis, I, ed. a cura d'Adela Mª Trepat i d'Anna Mª de Saavedra, Barcelona, Bernat Metge.

PETRARCA, Francesco (1992), Secretum, ed. a cura d'Enrico Fenzi, Milano, Mursia ("Gum, Nuova Serie", 213). 
- (1978), Obras, I. Prosa, ed. a cura de Francisco Rico, Madrid, Alfaguara.

RICO, Francisco (1982), "Para el Curial", dins Primera cuarentena y tratado general de Literatura, Barcelona, Quaderns Crema ("El Festín de Esopo"), pàgs. 89-90.

RIQUER, Martí de (1983), Los trovadores. Historia literaria y textos, 3 vols., Barcelona, Ariel ("Letras e ideas").

TURRÓ I TORRENT, Jaume (1991), "Sobre el Curial, Virgili i Petrarca", Estudis de Llengua i Literatura Catalanes, III (= Miscel-lània Joan Fuster), ed. d'Antoni Ferrando i Albert G. Hauf, Barcelona, Publicacions de l'Abadia de Montserrat, pàgs. 149-169. 